\title{
Dijagnostika ishemijske bolesti srca
}

\author{
Ivana Nedeljković, Jelena Stepanović, Miodrag Ostojić, Branko Beleslin, Vojislav Giga \\ Klinika za kardiologiju, Klinički centar Srbije; Medicinski fakultet, Univerzitet u Beogradu
}

\section{Suspektna i stabilna angina pektoris, bez prethodne revaskularizacije miokarda}

Kod svih bolesnika sa suspektnom ili stabilnom anginom pektoris potrebno je uraditi sledeće: detaljnu ana- mnezu i fizikalni pregled, EKG u miru, biohemijske analize krvi (lipidi, glukoza, kreatinin, urea, hepatogram, kompletna krvna slika, mokraćna kiselina, fibrinogen, hsCRP, itd.). Preporuke za laboratorijske analize kod bolesnika sa stabilnom anginom pektoris prikazane su u Tabeli 1.

Tabela 1. Preporuke za laboratorijske analize kod bolesnika sa stabilnom anginom pektoris ${ }^{1}$

\begin{tabular}{|c|c|c|}
\hline & $\begin{array}{c}\text { Klasa } \\
\text { preporuke }\end{array}$ & Nivo dokaza \\
\hline \multicolumn{3}{|c|}{ Preporuke za laboratorijske analize u inicijalnoj proceni angine pektoris (kod svih pacijenata) } \\
\hline Lipidni profil našte, ukupni holesterol, HDL, LDL i trigliceridi & I & B \\
\hline Glukoza našte & 1 & B \\
\hline Kompletna krvna slika: hemoglobin (Hb), leukociti & I & B \\
\hline Kreatinin & 1 & C \\
\hline \multicolumn{3}{|c|}{ Preporuke za laboratorijske analize u inicijalnoj proceni angine pektoris (zasnovane na kliničkoj prezentaciji) } \\
\hline \multicolumn{3}{|c|}{$\begin{array}{l}\text { Markeri miokardnog oštećenja ako evaluacija ukazuje na kliničku prezentaciju ne- } \\
\text { stabilnost ili akutni koronarni sindrom }\end{array}$} \\
\hline Markeri tireoidne funkcije ako je klinički indikovano & 1 & C \\
\hline Oralni test tolerancije glukoze & Ila & B \\
\hline hsCRP & IIb & B \\
\hline Lipoprotein A, apoA i ApoB & IIb & B \\
\hline Homocistein & Illb & B \\
\hline $\mathrm{HbA1c}$ & IIb & B \\
\hline NT-proBNP & IIb & B \\
\hline \multicolumn{3}{|c|}{ Preporuke za laboratorijske analize za rutinku ponovnu procenu u bolesnika sa hroničnom stabilnom anginom pektoris } \\
\hline Lipidni profil i glukoza našte jednom godišnje & Ila & C \\
\hline
\end{tabular}

Verovatnoća za postojanje stabilne angine pektoris može se izračunati na osnovu kliničkih karakteristika bola u grudima, godina starosti i pola bolesnika (Tabela 2). Tri najvažnije kliničke karakteristike bola u grudima su sledeće: 1. retrosternalna lokalizacija karakterističnog kvaliteta i trajanja, 2. provociranost fizičkim naporom ili emocionalnim stresom, 3. prestanak bola pri odmoru ili na primenu nitroglicerina. Na osnovu ovih karakteristika, bol u grudima se klasifikuje kao: 1. tipična ili definitivna angina pektoris - potrebno je da bol u grudima ima sve tri navedene karakteristike, 2. atipična ili moguća angina pektoris - bol ima dve od tri navedene karakteristike, 3. nekardijalni bol u grudima - postoji jedna ili nijedna od navedenih karakteristika.

Nakon orijentisanja o verovatnoći postojanja IBS (tzv. pretest verovatnoća u Bayes-ovoj teoremi), bolesnika možemo svrstati u jednu od tri kategorije prema verovatnoći za postojanje IBS: 1 . mala verovatnoća - manja od $10 \%$ (prema nekim autorima manja od $20 \%$ ), 2. srednja verovatnoća - 10-90\% (prema nekim autorima između 20 i 80\%), 3. visoka verovatnoća - veća od $90 \%$ (prema nekim autorima veća od $80 \%$ ). Bolesnike u grupi sa malom verovatnoćom za postojanje IBS nije potrebno dodatno ispitivati niti invazivnim niti neinvazivnim testovima (osim u slučaju ocena određenih sportskih/ profesionalnih sposobnosti); bolesnike u grupi sa srednjom verovatnoćom potrebno je testirati neinvazivnim funkcionalnim testovima kako bi se dokazalo postojanje inducibilne ishemije miokarda; dok je za bolesnike sa visokom verovatnoćom indikovana koronarna angiografija bez prethodnog neinvazivnog testiranja (Tabela 2). Ovo se preporučuje iz razloga što kod bolesnika sa ni- 
Tabela 2. Verovatnoća (u procentima) za postojanje IBS kod simptomatskih bolesnika (zelenom bojom je prikazana mala, žutom srednja, a crvenom visoka verovatnoća za postojanje IBS)

\begin{tabular}{|l|l|l|l|l|l|l|l|}
\hline \multicolumn{2}{|l|}{} & \multicolumn{2}{l|}{ Nekardijalni bol u grudima } & \multicolumn{2}{l|}{ Atipični anginozni bol } & \multicolumn{2}{l|}{ Tipični anginozni bol } \\
\hline Starost & $\overline{0}$ & muški & ženski & muški & ženski & muški & ženski \\
\hline $\mathbf{3 0 - 3 9}$ & 4 & 2 & 34 & 12 & 76 & 26 \\
\hline $\mathbf{4 0 - 4 9}$ & 13 & 3 & 51 & 22 & 87 & 55 \\
\hline $\mathbf{5 0 - 5 9}$ & 20 & 7 & 65 & 31 & 93 & 73 \\
\hline $\mathbf{6 0 - 6 9}$ & 27 & 14 & 72 & 51 & 94 & 86 \\
\hline
\end{tabular}

skom (odnosno visokom) pretest verovatnoćom za postojanje IBS, neinavazivno funkcionalno testiranje i u slučaju lažno pozitivnog (odnosno negativnog) rezultata i dalje daje nisku (odnosno visoku) post-test verovatnoću postojanja IBS koja utiče na donošenje kliničkih odluka nezavisno od rezultata testa. ${ }^{2}$

Pored otkrivanja IBS test fizičkim opterećenjem sa praćenjem EKG-a sam ili u kombinaciji sa vizualizacionim metodama (ehokardiografija, nuklearna, magnetna rezonanca) koristi se i za dokumentovanje ishemije kod bolesnika sa stabilnim simptomima, zatim radi stratifikacije rizika kod bolesnika sa stabilnom anginom. $\underline{\boldsymbol{U}}$ praksi dijagnostička i prognostička procena su neodvoiive. $^{3}$ Test fizičkim opterećenjem ima suštinsku važnost u odluci za eventualnu revaskularizaciju miokarda, imajući u vidu princip da je revaskularizacija indikovana samo ukoliko angiografski otkrivene stenoze koronarnih arterija imaju za posledicu ishemiju miokarda.

Test fizičkim opterećenjem je već decenijama dobro potvrđena i klinički opšte prihvaćena početna dijagnostička metoda koja se primenjuje kod bolesnika sa sumnjom na IBS ili pak kod bolesnika sa već postavljenom dijagnozom IBS, a kod kojih se test izvodi pre svega u prognostičke svrhe. Ovim testom može se otkriti IBS tek kada je aterosklerozom zahvaćeno više od $75 \%$ površine poprečnog preseka koronarne arterije (što odgovara suženju od 50\% dijametra stenoze). Izvodi se na ergobiciklu ili na pokretnoj traci (treadmillu) po standardizovanim protokolima. Dijagnostički test opterećenja izvodi se sa ciljem postavljanja (ili odbacivanja) dijagnoze IBS. Svim ispitanicima bi trebalo isključiti digoksin, beta-blokatore, antagoniste kalcijuma i nitrate, najmanje $24 \mathrm{~h}$ (optimalno 48h) pre izvođenja testa (pod uslovom da isključenje ovih lekova ne utiče značajno na zdravstveno stanje pacijenta). Beta blokatore bi trebalo isključiti postepeno.

Zbog visoke dostupnosti i niske cene, test fizičkim opterećenjem sa EKG monitoringom se najčešće koristi za potvrđivanje uzroka bola u grudima i obezbeđivanje objektivnog dokaza postojanja IBS. Glavno ograničenje testa fizičkim opterećenjem ili stresne elektrokardiografije je njena niska specifičnost (tj. veliki broj lažno pozitivnih rezultata, posebno kod žena posle menopauze, hipertoničara, hipertrofije leve komore, hiperlipidemije sa posledičnom endotelnom disfunkcijom). Osim toga, ne može se raditi kod bloka leve grane Hisovog snopa, WPW sindroma, nespecifičnih promena u ST segmentu i T talasu, kao i kod prisustva ritma pejsmejkera. U tim stanjima, prednost treba dati metodama u kojima se vi- zuelizuje funkcija ili perfuzija miokarda leve komore (stres ehokardiografija ili stres perfuziona scintigrafija). Primena ovih testova zavisi od opremljenosti ustanove i obučenosti kadra, a prednost treba dati testovima bez pratećeg jonizujućeg zračenja.

\section{Stres ehokardiografija}

Stres ehokardiografija je potvrđena metoda i tačnija je od EKG testa fizičkim opterećenjem u otkrivanju ishemije, jer se segmentni poremećaji kinetike zidova leve komore izazvani ishemijom javljaju pre EKG promena i angine, i zato što pruža mogućnost za lociranje ishemije (indirektno, krvni sud odgovoran za ishemiju) i procenu veličine ishemije (indeks pokretljivosti zidova leve komore - wall motion score index).

Najčešće korišćen stresor je fizičko opterećenje na ergobiciklu ili pokretnoj traci, ali se mogu upotrebiti i farmakološki stresori kao dobutamin, dipiridamol, adenozin, ergonovin, mentalni stres. Ako je moguće, najbolje je uraditi test fizičkim opterećenjem jer je to fiziološko opterećenje kojem su bolesnici najviše izloženi u svakodnevnom životu. Stres ehokardiografija zahteva adekvatnu edukaciju i iskustvo.Senzitivnost i specifičnost su približno 80-85\% i 84-86\%.Tehnička poboljšanja su uključila upotrebu kontrastnih agenasa, strain rate analizu. Glavno ograničenje metode predstavlja loš akustički prozor koji onemogućava adekvatnu interpretaciju segmentne kinetike ${ }^{2}$.

\section{Perfuziona scintigrafija (SPECT)}

SPECT je potvrđeni dijagnostiči test koji omogućava senzitivniju i specifičniju predikciju prisustva IBS nego EKG test fizičkim opterećenjem. U osnovi metode leži dokazivanje heterogenosti protoka, a izazivanje same ishemije nije neophodno. Upravo se ovim može objasniti velika senzitivnost metode (85-90\%), a relativno mala specifičnost (70-75\%), u poređenju i sa stresnom ehokardiografijom. Takođe, pri korišćenju metode treba imati u vidu i prisustvo jonizujućeg zračenja.

\section{Kardiovaskularna magnetna rezonanca (MRI)}

Kardiovaskularni MRI stres test sa farmakološkim stresorom može da se koristi za otkrivanje poremećaja segmentne kinetike zidova leve komore indukovanih infuzijom dobutamina ili adenozina.

Ova metoda se primenjuje od skoro u kliničkoj praksi sa samo nekoliko publikovanih radova koji porede MRI 
sa drugim neinvazivnim vizualizacionim tehnikama. Skora metaanaliza pokazala je da su stresom indukovani poremećaji kinetike tokom MRI imali senzitivnost od $83 \%$ i specifičnost od $86 \%$, i perfuziona vizualizaciona metoda $91 \%$ senzitivnosti i $81 \%$ specifičnosti ${ }^{4}$. Kada je sprovedeno prospektivno ispitivanje na više mesta, dijagnostička vrednost stres perfuzione MRI pokazala je sličnu visoku senzitivnost, ali nižu specifičnost.

\section{Pozitron emisiona tomografija}

Studije sa PET ispitivanjem miokardne perfuzije pokazale su odlične dijagnostičke mogućnosti u otkrivanju IBS. Poređenja PET perfuzione metode je pokazalo prednost PET u odnosu na SPECT. Metaanalize podataka dobijenih pomoću PET pokazale su $92 \%$ senzitivnosti i $85 \%$ specifičnosti za otkrivanje IBS, što je superiornije u odnosu na SPECT. Miokardni protok krvi u apsolutnim jedinicama $(\mathrm{mL} / \mathrm{g} / \mathrm{min})$ meren pomoću PET dodatno poboljšava dijagnostiču tačnost posebno kod bolesnika sa mikrovaskularnom bolešću i može se koristiti za praćenje efekta terapije ${ }^{3,5}$.

\section{Hibridne/kombinovane vizualizacione tehnike}

Termin hibridna vizualizacija ukazuje na vizualizacioni sistem u kome se koriste dva modaliteta [MDCT i PET, MDCT i single photon emission computed tomography (SPECT)] koje se kombinuju na istom skeneru (prikazujući anatomiju epikardijalnih arterija, kao i miolkardni metabolizam i perfuziju).

Kombinacija anatomskog i funkcionalnog ispitivanja je veoma značajna zbog prostorne korelacije anatomskih i funkcionalnih informacija udruženog posmatranja mogu da olakšaju interpretaciju koronarnih lezija i njihovog patofiziološkog značaja. Ova kombinacija se može postići metodom koja ima dva kombinovana modaliteta o (MDCT i SPECT, MDCT i PET). Ispitivanje je izvodljivost i tačnost kombinovanog MDCT i perfuzione tehnike. Pokazalo je nezavisne prognostičke informacije. Rezultati velikih multicentričnih studija nisu poznati ${ }^{3}$. U Tabeli 2.4 prikazane su preporuke za primenu testova optereće- njem sa vizualizacionim tehnikama u inicijalnoj dijagnostici IBS.

Neinvazivni funkcionalni dijagnostički testovi, pored dijagnostičkog, imaju i veliki prognostički značaj. Prognostički test fizičkim opterećenjem izvodi se u cilju procene terapijskog efekta medikamentne terapije ili ravaskularizacije miokarda, pa isključenje antianginoznih lekova pre testiranja nije potrebno. Čak i sama činjenica da bolesnik ne može da izvede test fizičkim opterećenjem već ukazuje na nešto lošiju prognozu.

Za 24h Holter EKG-a važe slična ograničanja kao i za EKG u opterećenju, a indikacije za njegovu primenu su bolesnici sa suspektnom vazospastičnom anginom pektoris (Prinzmetal) (klasa preporuka lla, nivo dokaza C) kao i bolesnici sa anginom pektoris i pridruženim poremećajima srčanog ritma (klasa preporuka I, nivo dokaza B).

Nije dokazana korist rutinske rendgengrafije srca i pluća kod svih bolesnika sa IBS, mada se preporučuje kod bolesnika sa ishemijskom kardiomiopatijom (klasa preporuke I, nivo dokaza C) i kod bolesnika sa klinički dokazanom značajnom bolešću pluća (klasa preporuke I, nivo dokaza B).

Multidetektorska kompjuterizovana tomografija (MDCT) je relativno dobra metoda za vizuelizaciju koronarnih arterija, dok je magnetna rezonanca (MRI) superiorna u prikazivanju strukture miokarda. Pokazano je da MDCT ima visoku negativnu prediktivnu vrednost, sugerišući da je MDCT odlična metoda za isključivanje IBS, dok je njena pozitivna prediktivna vrednost umerena. MDCT angiografija ne može precizno da predvidi hemodinamski značaj koronarne stenoze, s obzirom na to da ne uzima u obzir veličinu perfuzionog polja distalno od stenoze. Dostupnost ove tehnologije i prohodnost bolesnika je relativno mala u Srbiji, u poređenju sa drugim neinvazivnim dijagnostičkim testovima, i uglavnom je rezervisana za bolesnike koji se tim drugim testovima ne mogu evaluirati (npr. loš akustički prozor).

Kombinacija anatomskog i funkcionalnog ispitivanja je veoma interesantan koncept koji kod nas još uvek nije zaživeo, i za sada se primenjuje u malom broju centara u svetu. Ova kombinacija se može postići uređajima koji imaju integrisane dve različite viualizacione tehnike (MDCT i SPECT; MDCT i PET).

Tabela 3. Preporuke za izvođenje testa fizičkim opterećenjem sa EKG-om ${ }^{1}$

\begin{tabular}{|c|c|c|}
\hline & Klasa & Nivo dokaza \\
\hline \multicolumn{3}{|c|}{$\begin{array}{l}\text { Preporuke za izvođenje testa fizičkim opterećenjem sa EKG-om (isklučuje se stres-eho i talijum-scintigrafija) za } \\
\text { inicijalno dijagnostovanje angine pectoris }\end{array}$} \\
\hline $\begin{array}{l}\text { Pacijenti sa simptomima angine pectoris i srednjom pre-test verovatnoćom za posto- } \\
\text { janje IBS (videti Bayesovu teoremu, Poglavlje 3.2). Ovo podrazumeva sve one bole- } \\
\text { snike određene godinama, polom ili simptomima, uključujući i one koji imaju kom- } \\
\text { pletan blok desne grane ili ST-depresiju <1mm u miru. }\end{array}$ & I & B \\
\hline Pacijenti koji uzimaju digokisn ili EKG u miru sa ST-depresijom $\geq 1 \mathrm{~mm}$ & & B \\
\hline $\begin{array}{l}\text { Pacijenti sa malom pre-test verovatnoćom }(<10 \%) \text { za IBS, određeno prema godina- } \\
\text { ma, polu i simptomima }\end{array}$ & $\mathrm{IIb}$ & B \\
\hline \multicolumn{3}{|c|}{$\begin{array}{l}\text { Preporuke za izvođenje testa fizičkim opterećenjem sa EKG-om za rutinsku ponovnu procenu u pacijenata sa } \\
\text { hroničnom stabilnom anginom }\end{array}$} \\
\hline Rutinski periodičan test opterećenja sa EKG-om u odsustvu kliničkih promena & IIb & $\mathrm{C}$ \\
\hline
\end{tabular}


Tabela 4. Preporuke za primenu testa fizičkim opterećenjem sa vizuelizacionim tehnikama ${ }^{1}$

\begin{tabular}{|c|c|c|}
\hline & Klasa & Nivo dokaza \\
\hline \multicolumn{3}{|c|}{$\begin{array}{l}\text { Preporuke za primenu testa fizičkim opterećenjem sa vizuelizacionim tehnikama (ehokardiografija ili nuklear } \\
\text { ne metode) u početnoj dijagnostici angine pectoris }\end{array}$} \\
\hline $\begin{array}{l}\text { Stres ehokardiografija sa testom fizičkim opterećenjem kod bolesnika sa srednjom pre- } \\
\text { test verovatnoćom za koronarnu bolest koji imaju jednu od sledećih promena na EKG-u } \\
\text { u miru: } \\
\text { - WPW sindrom (sindrom preekscitacije) } \\
\text { - ST-depresija u miru } \geq 1 \mathrm{~mm} \\
\text { - LBBB (blok leve grane) } \\
\text { - Ritam pejsmejkera }\end{array}$ & I & $B$ \\
\hline $\begin{array}{l}\text { Bolesnici sa inkonkluzivnim testom fizičkim opterećenja na EKG-u, kod kojih postoji ve- } \\
\text { lika verovatnoća postojanja koronarne bolesti, a gde je dijagnoza još uvek suspektna }\end{array}$ & I & B \\
\hline $\begin{array}{l}\text { Bolesnici sa prethodnom revaskualrizacijom miokarda (PCI ili CABG) kod kojih je lokali- } \\
\text { zacija ishemije značajna }\end{array}$ & I & $A$ \\
\hline $\begin{array}{l}\text { Farmakološki stres-test (dobutamin, adenozin, dipiridamol) kod bolesnika sa srednjom } \\
\text { pretest verovatnoćom za IBS koji nisu sposobni da izvedu adekvatan test fizičkim opte- } \\
\text { rećenjem }\end{array}$ & I & $B$ \\
\hline $\begin{array}{l}\text { Bolesnici sa malom pretest verovatnoćom za postojanje IBS, kao što su žene sa atipič- } \\
\text { nim bolom u grudima }\end{array}$ & Ila & B \\
\hline Procena funkcionalne značajnosti intermedijarnih lezija nakon koronarne arteriografije & Ila & $\mathrm{C}$ \\
\hline $\begin{array}{l}\text { Za određivanje lokalizacije ishemije miokarda kada se planira opcija revaskularizacije } \\
\text { (PCI ili CABG) kod bolesnika koji već imaju urađenu arteriografiju }\end{array}$ & Ila & B \\
\hline
\end{tabular}

\section{Invazivni testovi}

Selektivna koronarna arteriografija, koja predstavlja luminogram, odnosno odraz onoga što ateroskleroza "radi” lumenu krvnog suda, je za dugo je bila „zlatni” standard u dijagnostici IBS. Međutim, još su neinvazivni testovi za provokaciju miokardne ishemije pokazali da se kod mnogih intermedijarnih angiografskih stenoza ne može predvideti rezultat testa.

Uobičajena je praksa da mnogi bolesnici sa visokom pretest verovatnoćom za IBS budu upućeni na kateterizaciju srca bez predhodnog funkcionalnog testiranja. Kada su neinvazivni testovi za ocenu hemodinamskog značaja koronarne stenoze putem provokacije miokar-

Tabela 5. Indikacije različitih vizuelizacionih testova za dijagnozu koronarne bolesti i za procenu prognoze kod pacijenata bez utvrđene koronarne boelsti ${ }^{3}$

\begin{tabular}{|c|c|c|c|c|c|c|}
\hline & $\begin{array}{l}\text { Asimptomat- } \\
\text { ska IBS (skri- } \\
\text { ning) }\end{array}$ & \multicolumn{3}{|c|}{ Simptomatska IBS } & \begin{tabular}{|l|} 
Prognostička \\
vrednost za \\
pozitivan \\
rezultat $^{\text {b }}$ \\
\end{tabular} & \begin{tabular}{|l} 
Prognostička \\
vrednost za \\
negativan \\
rezltatc $^{c}$ \\
\end{tabular} \\
\hline & & \multicolumn{3}{|c|}{$\begin{array}{l}\text { Pretest verovatnoća }{ }^{a} \text { za značajnu koronarnu } \\
\text { stenozu }\end{array}$} & & \\
\hline & & mala & srednja & visoka & & \\
\hline \multicolumn{7}{|l|}{ Anatomski test } \\
\hline $\begin{array}{l}\text { Invazivna angio- } \\
\text { grafija }\end{array}$ & IIIA & IIIA & IIbA & IA & IA & IA \\
\hline MDCT angiografija & $\mathrm{IIIB}^{\mathrm{c}}$ & $\mathrm{IIbB}$ & IlaB & IIIB & IIbB & IlaB \\
\hline MRI & IIIB & IIIB & IIIB & IIIB & IIIC & IIIC \\
\hline \multicolumn{7}{|l|}{ Funkcionalni test } \\
\hline Stres eho & IIIA & IIIA & IA & $I I I A^{d}$ & IA & IA \\
\hline Nuklearni imidžing & IIIA & IIIA & IA & IIIA $A^{d}$ & IA & IA \\
\hline Stres MRI & IIIB & IIIB & IlaB & ${ }^{\prime I I B^{d}}$ & IlaB & IlaB \\
\hline PET & IIIB & IIIB & IlaB & $I I I B^{d}$ & IlaB & IlaB \\
\hline
\end{tabular}


dne ishemije kontraindikovani, nedijagnostički ili nedostupni, predlaže se određivanje frakcione rezerve protoka (FFR) ciljne epikardne koronarne stenoze (klasa preporuke I, nivo dokaza A). Čak i iskusni interventni kardiolozi ne mogu precizno da predvide značajnost većine intermedijarnih stenoza samo na bazi vizuelne procene ili kvantitativne koronarne angiografije. Odlaganje perkutane koronarne intervencije ili hirurške revaskularizacije kod bolesnika sa vrednošću FFR-a preko 0,80 (što predstvlja $80 \%$ od protoka kada ne bi postojala stenoza na koronarnoj arteriji) bezbedno je i njihov klinički tok je odličan. S obzirom na cenu i manju dostupnost opreme i koronarnih žica za određivanje FFR-a, u našim uslovima se pokazalo kao jako korisno određivanje koronarne rezerve protoka (CFR) transtorakalnim Dopplerskim ultrazvučnim pregledom uz intravensko davanje adenozina. Naročito je dobra negativna prediktivna vrednost za CFR veći od 2,0. Nedostatak ove metode je da ima nezadovoljavajuću izvodljivost u slučaju evaluacije cirkumfleksna koronarne arterije (LAD arterija se ovim putem može evaluirati u preko $90 \%$, a RCA u $80 \%$ slučajeva), kao i da mnogo zavisi od bazalnih hemodinamskih parametara i kvaliteta miokardne mikrocirkulacije.

U Tabeli 5 dat je sumaran pregled različitih neinvazivnih i invazivnih metoda u dijagnozi i prognozi koronarne bolesti.

a-Za prognostičko ispitivanje koronarne stenoze, funkcionalne vizuelizacione tehnike imaju slične indikacije

b - Pretest verovatnoća za otkrivanje IBS izračunata na osnovu simptoma, pola i godina starosti

$c-U$ odnosu na MDCT angiografiju, a ne na kalcijumski skor

d - Kod bolesnika sa opstruktivnom koronarnom bolešću potvrđenom angiografski, funkcionalno testiranje može biti korisno za utvrđivanje revaskularizacione strategije bazirano na stepenu, ozbiljnosti i lokalizaciji ishemije

\section{Praćenje bolesnika nakon revaskularizacije miokarda}

Sa upotrebom stentova obloženih lekom (DES) kod perkutane revaskularizacije i arterijskih graftova kod hirurške revaskularizacije miokarda, potreba za otkrivanjem restenoze se generalno smanjila. Međutim, strategija za praćenje bolesnika nakon revaskularizacije ne treba da se fokusira samo na otkrivanje restenoze ili okluzije graftova, već i na procenu funkcionalnog statusa bolesnika, kao i na sekundarnu prevenciju. U tom smislu, strategija evaluacije bolesnika nakon revaskularizacije miokarda obuhvata dve velike oblasti: praćenje bolesnika u smislu detekcije restenoze/okluzije graftova/progresije ateroskleroze i evaluacija bazalnog funkcionalnog kapaciteta koji je potreban kada se ulazi u rehabilitacioni program nakon revaskularizacije.

Fizikalni pregled, EKG u miru i osnovne laboratorijske analize se preporučuju unutar 7 dana od $\mathrm{PCl}$, uz pregled mesta punkcije, kontrolu hemodinamskih parametara, krvne slike i eventualno bubrežne funkcije koji ukazuju na pojavu CIN-a. Kod bolesnika sa AKS, lipide treba kontrolisati 4-6 nedelja posle akutnog događaja i/ili započinjanja terapije statinima, u cilju evaluacije efekata i eventualnih neželjenih dejstava terapije statinima. Saledeća kontrola plazma lipida je posle 3 meseca, a enzime jetre treba prekontrolisati inicijalno i posle 8-12 nedelja.

Ostaje otvoreno pitanje da li i kada treba raditi test fizičkim opterećenjem posle revaskularizacije kod asimptomataskih bolesnika. Prema preporukama, smatra se da kod ovih bolesnika nema potrebe za testom, mada postoje i autori koji ukazuju na značaj neme ishemije. Rani test opterećenjem preporučuje se kod inkompletne ili suboptimalne revaskularizacije, kao i kod posebnih populacija bolesnika (Tabela 5). Stres ehokardiografski test ili perfuziona scintigrafija imaju prednost nad rutinskim testom opterećenja zbog značajno veće dijagnostičke vrednosti, lokalizacije ishemije i praćenja povoljnih efekata revaskularizacije. Izbor testa i vizuelizacione tehnike zasniva se na istim proncipima kao i kod bolesnika pre revaskularizacije. Bolesnici koji su imali $\mathrm{PCl}$ na glavnom stablu leve koronarne arterije mogu se uputiti na kontrolni MSCT ili angiografiju u roku od 3 do 12 meseci. Preporuke za strategije praćenja za asimptomatske i simptomatske bolesnike nakon revaskularizacije miokarda date su u Tabelama 6 i 7.

*Kod specifičnih grupa bolesnika indikovan je rani test opterećenja:

- Pred otpust ili neposredno nakon otpusta kod bolesnika sa STEMI lečenih pPCI ili hitnom CABG

- Kod bolesnika koji se bave profesijama koje mogu ugroziti bezbednost drugih ljudi (npr. piloti , vozač, ronioci) i kod profesionalnih sportista

- Bolesnici koji koriste inhibitore 5 fosfodiesteraze

Tabela 6. Strategije praćenja i vođenje asimptomatskih pacijenata nakon revaskularizacije miokarda³

\begin{tabular}{|l|c|c|}
\hline & Klasa & Nivo dokaza \\
\hline $\begin{array}{l}\text { Stres testove sa vizuelizacijom funkcije/perfuzije miokarda (stres-eho test ili SPECT) } \\
\text { treba raditi pre nego stres-EKG test }\end{array}$ & I \\
\hline $\begin{array}{l}\text { - kod bolesnika sa procenjenim niskim rizikom (+) na stres-eho testu savetuje se poja- } \\
\text { čanje OMT i promena životnih navika } \\
\text { - kod bolesnika sa procenjenim visokim ili srednjim rizikom (++) na stres-eho testu pre- } \\
\text { poručuje se koronarografija }\end{array}$ & Ila \\
\hline Rano testiranje sa imidžing tehnikom se preporučuje kod specifičnih grupa bolesnika* & Ila & C C \\
\hline Rutinski stres test treba raditi nakon 2 godine posle PCli $\geq 5$ godina nakon CABG & IIb & C \\
\hline
\end{tabular}


Tabela 7. Strategije praćenja i lečenje simptomatskih bolesnika nakon revaskularizacije miokarda [3]

\begin{tabular}{|c|c|c|}
\hline & Klasa & Nivo dokaza \\
\hline $\begin{array}{l}\text { Stres testovi sa vizuelizacionom tehnikom (stres-eho test i SPECT) treba raditi pre nego } \\
\text { stres-EKG test }\end{array}$ & 1 & A \\
\hline $\begin{array}{l}\text { Kod bolesnika sa znacima niskog rizika (+) na stres testu savetuje se pojačanje medika- } \\
\text { mentne terapije i promena životnih navika }\end{array}$ & 1 & B \\
\hline $\begin{array}{l}\text { Kod bolesnika sa znacima visokog ili srednjeg rizika (++) na stres testu preporučuje se } \\
\text { koronarografija }\end{array}$ & 1 & $\mathrm{C}$ \\
\hline Kod bolesnika sa STEMI savetuje se hitna koronarografija & 1 & A \\
\hline Kod visoko rizičnih bolesnika sa NSTEMI-AKS indikovana je rana invazivna strategija & $\mathrm{I}$ & A \\
\hline Kod niskorizičnih bolesnika sa NSTEMI-AKS indikovana je elektivna koronarografija & 1 & $\mathrm{C}$ \\
\hline
\end{tabular}

(+) Test sa znacima niskog rizika jesu testovi sa ishemijom na visokom stepenu opterećenja, sa kasnom pojavom ishemije, ishemijom u jednoj zoni miokarda sa blažim stepenom ispada kinetike zidova ili manji reverzibilni perfuzoni defekt, ili test bez dokazane ishemije.

$(++)$ Test sa znacima umerenog ili visokog rizika je test sa provociranom ishemijom na niskom stepenu opterećenja, rana pojava ishemije, ishemija u više zona sa težim stepenom poremećaja segmentne kinetike ili reverzibilni perfuzioni defekt.

- Bolesnici koji bi se rekreativno bavili aktivnošću koja zahteva veliku potrošnju kiseonika

- Bolesnici koji su imali srčani zastoj

- Bolesnici sa nekompletnom ili suboptimalnom revaskularizacijom čak iako su asimptomatski

- Bolesnici sa komplikacijama tokom revaskularizacije (perioperativni AIM, velika disekcija tokom $\mathrm{PCl}$, endarterektomija tokom CABG, itd.)

- Dijabetičari (posebno insulin-zavisni)

- Bolesnici sa multivaskularnom koronarnom bolešću i rezidualnim intermedijarnim lezijama ili sa "silent" ishemijom

\section{Literatura}

1. Fox K, Garcia MA, Ardissino D, et al. Guidelines on the management of stable angina pectoris: executive summary: The Task Force on the Management of Stable Angina Pectoris of the European Society of Cardiology. Eur Heart J, 2006; 27 (11): 1341-81.

2. Ostojic, M. i sar. Preporuke za prevenciju ishemijske bolesti srca. Nacionalni komitet za izradu Vodica klinicke prakse u Srbiji. Beograd: Ministarstvo zdravlja Republike Srbije, 2002.

3. Wijns W, Kolh P, Danchin N, et al. Guidelines on myocardial revascularizationThe Task Force on Myocardial Revascularization of the EuropeanSociety of Cardiology (ESC) and the European Association forCardio-Thoracic Surgery (EACTS). European Heart Journal 2010; 31: 2501-2555.

4. Nandalur KR, Dwamena BA, Choudhri AF, Nandalur MR, Carlos RC. Diagnosticperformance of stress cardiac magnetic resonance imaging in the detection ofcoronary artery disease: a metaanalysis. J Am Coll Cardiol 2007; 50: 1343-1353.

5. Bateman TM, Heller GV, McGhie Al, , et al. Diagnostic accuracy of rest/stress ECG-gated Rb-82 myocardial perfusion PET: comparison with ECG-gatedTc-99m sestamibi SPECT. J Nucl Cardiol 2006; 13: 24-33. 